\title{
Lung cinescintigraphy in the dynamic assessment of ventilation and mucociliary clearance of asbestos cement workers
}

Luigi Di Lorenzo, Marino Mele, Massimo M Pegorari, Angelo Fratello, Carlo Zocchetti, Daniela Capozzi

\begin{abstract}
Objectives-To verify in vivo whether lung cinescintigraphy confirms the effect of asbestos on the patency of the smallest airways and on the efficiency of mucociliary clearance in asbestos cement workers.
\end{abstract}

Methods-39 male subjects were examined: 30 asbestos cement workers and nine workers never exposed to occupational respiratory irritants. All subjects had a chest radiograph (International Labour Organisation (ILO) 1980); standard questionnaire on chronic bronchitis; spirometry; arterial blood gas analysis; carbon monoxide transfer factor $\left(\mathrm{TLCO}_{\mathrm{sb}}\right)$; pulmonary $\mathrm{O}_{2}$ and $\mathrm{CO}_{2}$ ductances $\left(\mathrm{DuO}_{2}, \mathrm{DuCO}_{2}\right)$; electrocardiogram; and lung cinescintigraphy after radioaerosol inhalation for the measurement of mucociliary clearance time in vivo in the smallest ciliated airways and for the assessment of radioaerosol deposition in alveoli (alveolar deposition index).

Results-Apart from nine non-exposed subjects, the 30 asbestos cement workers were so classified on the basis of chest radiography: nine of them as healthy exposed, 10 with pleural plaques, and 11 with asbestosis. The four groups had similar ages, work seniority, and smoking habits. Exercise dyspnoea was significantly more frequent in asbestos cement workers. Lung function variables of workers with effects related to asbestos were significantly lower than the other two groups. The $\mathrm{PaO}_{2}, \mathrm{TLCO}_{\mathrm{sb}}$ and $\mathrm{DuO}_{2}$ mean values were significantly lower in exposed workers than non-exposed. The mean $\mathrm{PaCO}_{2}$ value was significantly higher in the asbestosis group than in the other three groups. Workers with effects related to asbestos showed a significantly lower alveolar deposition index and a significantly higher mucociliary clearance time than the other two groups. Subjects with asbestosis showed similar differences from those with pleural plaques.

Conclusions-Lung cinescintigraphy confirms in vivo the effects of asbestos on bronchiolar and alveolar patency and on efficiency of mucociliary clearance in the smallest ciliated airways. Finally, lung cinescintigraphic variables are able to discriminate workers with asbestosis from those with pleural plaques.

(Occup Environ Med 1996;53:628-635)
Keywords: asbestos cement workers; mucociliary clearance; lung cinescintigraphy

In parenchymal asbestosis, the characteristic diffuse reticular linear fibrosis of the small interstitium is preceded and accompanied by fibrosis of the walls of the small airways, such as the terminal and respiratory bronchioles, as has been found in necrobioptic studies performed on the lungs of chrysotile asbestos miners. ${ }^{1}$ These lesions, along with cellular infiltrates and peribronchiolar fibrosis, ${ }^{2}$ cause obstruction of the small airways, ${ }^{34}$ which has long been considered an early sign of parenchymal asbestosis. ${ }^{5}$

Also, the mucosa of the terminal bronchioles is normally covered by a cuboid epithelium, which still has vibratile cilia, where the Clara secreting cells progressively replace the globet cells. Thus, xenobiotics can be removed from the proximal zones of the lower respiratory tract both by mucociliary clearance and by macrophage activity (pulmonary clearance) ${ }^{6}$

Asbestos fibres $<5 \mu \mathrm{m}$ and especially fibres $<2.0-2.5 \mu \mathrm{m}$ deposit preferentially on the bifurcations of the alveolar ducts, where they can be phagocytised by macrophages. ${ }^{6}$ Pulmonary clearance is slow, requiring one or more months for completion. With amoeboid movements, some alveolar macrophages, with their fibre load, can reach the ciliated bronchioles and then be removed through mucociliary clearance. ${ }^{7}$ Clearance also removes the larger asbestos fibres ${ }^{8}$ that are deposited in the upper airways. Mucociliary clearance, which is completed in less than 24 hours, therefore contributes to the rather rapid elimination of some of the asbestos deposited in the lungs. In fact, experimental in vitro studies on hamster tracheae showed that asbestos fibres $>10 \mu \mathrm{m}-$ that is, those with greater pathogenic activity-are initially removed by mucociliary clearance, whereas the shorter fibres can be retained by the mucosa. ${ }^{9}$ With prolonged exposure and depending on the dose, asbestos fibres seriously affect the ciliated epithelium, causing progressive squamous metaplasia, which is further exacerbated by smoking. ${ }^{10}$

Such morphological alterations produce impairment of mucociliary clearance and therefore an increase in retention of mucus and asbestos fibres in the airways. ${ }^{8}$

The present study was aimed at verifying in vivo whether radioaerosol inhalation cinescintigraphy of the lung confirms the adverse effect of asbestos on the patency of the small airways and on the efficiency of mucociliary clearance in chronically exposed workers.

Bari, Italy.

Accepted for publication

14 March 1996 
Materials and methods

We recruited the exposed subjects from a union, 35 male members of which were exworkers in an asbestos cement factory ${ }^{\star}$. All subjects were informed about the procedures and the aims of our study and 30 out of 35 agreed to participate and form our group of exposed subjects. Nine more male volunteers, belonging to the same syndicate but never exposed to respiratory irritant dust or fumes, formed our control group.

The asbestos cement was a mixture of $80 \%$ cement and $20 \%$ asbestos. The asbestos mixtures consisted of $70 \%-80 \%$ chrysotile, $15 \%-20 \%$ crocidolite, and the rest amosite.

Informed consent was obtained from all the participants before the beginning of the study, which was approved by the local ethics committee.

All subjects had chest $x$ ray films performed in posterior anterior, lateral, and oblique projections, which were read double blind, according to International Labour Organisation (ILO) 1980 standards, ${ }^{11}$ by a radiologist and an occupational physician, and medical reports were always concordant.

All subjects were also given a standard questionnaire on chronic bronchitis, ${ }^{12}$ and underwent a general medical examination, slow and forced dynamic spirometry, performed according to American Thoracic Society (ATS) standards, ${ }^{13}$ arterial blood gas analysis, carbon monoxide transfer factor $\left(\mathrm{TLCO}_{\mathrm{sb}}\right)$, measurement of global pulmonary $\mathrm{O}_{2}$ and $\mathrm{CO}_{2}$ ductances $\left(\mathrm{DuO}_{2}\right.$ and $\left.\mathrm{DuCO}_{2}\right),{ }^{145}$ and an electrocardiogram. The reference values of spirometric variables and $\mathrm{TLCO}_{\mathrm{sb}}$ were those of the European Community for Coal and Steel (ECCS). ${ }^{16}$ Slow spirometry, performed seated, helped to establish the tidal volume and respiratory frequency at rest. Measurement of ductance coefficients was performed as they allow verification in steady state of lung efficiency in ensuring exchange of both respiratory gases.

For diagnostic purposes all subjects inhaled an ultrasonically generated ${ }^{99 \mathrm{~m}} \mathrm{Tc}$ human serum albumin aerosol (mean aerodynamic diameter $2.5 \mu \mathrm{m}$; range $1.5-4.0 \mu \mathrm{m}$; SD 1.75 $\mu \mathrm{m})$, for the measurement of mucociliary clearance time in vivo and for assessment of alveolar deposition of radioaerosol. ${ }^{17}$

Each subject performed the test for nine to 12 minutes in an upright seated position, with spontaneous ventilation, through a mouthpiece with the nose clipped, at the same tidal volume and breathing frequency measured by the previously performed spirometry. The ventilation was monitored during radioaerosol inhalation by a pneumotachograph (connected in series to the tank from which the aerosol was inhaled). In this way we tried to avoid any false intrapulmonary distribution of the aerosol as a consequence of ventilatory regimes that were unusual for the individual subject. After inhalation, the workers rinsed their mouths and then drank some water to

${ }^{\star}$ A Republic President's Decree (DPR n 257, March 27th, 1992) prohibits industrial use of asbestos in Italy. clean the oropharynx and oesophagus of deposited radioaerosol. Smokers abstained from smoking for at least two hours before radioaerosol inhalation, but smoking was permitted from 24 hours afterwards. None of the subjects took any drugs in the two weeks before the clinical and instrumental tests.

Immediately after the aerosol, each subject lay supine on the bed under the gamma camera equipped with a general purpose collimator with parallel holes and connected to a computer. In the first two hours 120 images of 60 seconds each, in a $64 \times 64$ pixels matrix, were collected; 24 hours after the end of the aerosol an image was obtained every 60 seconds for 10 minutes. Mucociliary clearance, which acts in the ciliated airways, ensures clearance of exogenous particles in a short time and in any case within 24 hours. ${ }^{18}$ Radioactivity in the lungs 24 hours after the end of the aerosol is an expression of the amount of particles deposited exclusively in the most peripheral airways (alveolar deposition index) ${ }^{19}$ where the only clearance is by macrophages, which requires several weeks to accomplish. ${ }^{20}$ That is why the radioaerosol deposited in the alveoli can be considered as constant during the first 24 hours. When, for each subject, we deducted this alveolar deposition index from all the 120 measurements obtained in the 120 minutes after the radioaerosol the resulting radioactivity deposited in the small ciliated airways could be used to study mucociliary clearance. ${ }^{21}$ Lastly, we created regions of interest on both lungs and activity-time curves, which we normalised and corrected by the physical decay of ${ }^{99 \mathrm{~m}} \mathrm{Tc}$. Subsequent analysis of the data obtained was performed on the regions of interest of the right lung only, so as to avoid interference on the left lung of any radioactive particles accidentally swallowed and present in the stomach. ${ }^{22}$

The appendix describes the method of developing a mathematical model to foresee mucociliary clearance time and the alveolar deposition index.

The patients were asked to avoid coughing during lung cinescintigraphy.

To assess the correct application of the method, six subjects, two from the control group and four from the exposed group, selected randomly, underwent a second test two months after the first, with the same procedure.

\section{STATISTICAL ANALYSIS}

The reproducibility of the results of the six

Table 1 Comparison of mean age and work seniority in the four groups of workers ( $A N O V A$ )

\begin{tabular}{|c|c|c|c|c|c|}
\hline & $n$ & Mean & $S D$ & $\begin{array}{l}\text { Min- } \\
\operatorname{Max}\end{array}$ & $A N O V A$ \\
\hline \multicolumn{6}{|l|}{ Age (y): } \\
\hline Non-exposed & 9 & $44 \cdot 7$ & $15 \cdot 8$ & $26-62$ & $F=1.52$ \\
\hline Healthy exposed & 9 & $47 \cdot 0$ & $6 \cdot 1$ & $38-55$ & \\
\hline Pleural plaques & 10 & $54 \cdot 5$ & $6 \cdot 5$ & $47-65$ & \\
\hline Asbestosis & 11 & $50 \cdot 5$ & $11 \cdot 7$ & $35-75$ & \\
\hline \multicolumn{6}{|c|}{ Work seniority $(y)$ : } \\
\hline Non-exposed & 9 & $25 \cdot 4$ & $10 \cdot 4$ & $7-40$ & $F=1 \cdot 10$ \\
\hline Healthy exposed & 9 & $21 \cdot 9$ & $7 \cdot 9$ & $13-36$ & NS \\
\hline Pleural plaques & 10 & $23 \cdot 5$ & $7 \cdot 4$ & $16-37$ & \\
\hline Asbestosis & 11 & $18 \cdot 9$ & $7 \cdot 7$ & $12-33$ & \\
\hline
\end{tabular}


Table 2 Smoking and history of chronic phlegm and exercise dyspnoea in the four groups ( $\chi^{2}$ test)

\begin{tabular}{|c|c|c|c|c|c|c|}
\hline & $\begin{array}{l}\text { Non-exposed } \\
n=9\end{array}$ & $\begin{array}{l}\text { Healthy } \\
\text { exposed } \\
n=9\end{array}$ & $\begin{array}{l}\text { Pleural } \\
\text { plaques } \\
n=10\end{array}$ & $\begin{array}{l}\text { Asbestosis } \\
n=11\end{array}$ & $\begin{array}{l}\text { Totals } \\
n=39\end{array}$ & $\stackrel{\chi^{2}}{T e s t}$ \\
\hline \multicolumn{7}{|l|}{ Smoking: } \\
\hline Non-smokers & $4(44 \cdot 4)$ & $3(33 \cdot 3)$ & $3(30 \cdot 0)$ & $3(27 \cdot 3)$ & $13(33 \cdot 3)$ & $\chi^{2}=2.68$ \\
\hline Ex-smokers & $2(22 \cdot 2)$ & $3(33 \cdot 3)$ & $2(20 \cdot 0)$ & $5(45 \cdot 4)$ & $12(30 \cdot 8)$ & NS \\
\hline Smokers & $3(33.3)$ & $3(33 \cdot 3)$ & $5(50 \cdot 0)$ & $3(27 \cdot 3)$ & $14(35 \cdot 9)$ & \\
\hline \multicolumn{7}{|l|}{ Chronic phlegm: } \\
\hline Absent & $6(66 \cdot 7)$ & $3(33 \cdot 3)$ & $2(20 \cdot 0)$ & $4(36 \cdot 4)$ & $15(38 \cdot 5)$ & $\chi^{2}=4.58$ \\
\hline \multirow{2}{*}{\multicolumn{7}{|c|}{ Exercise dyspnoea: }} \\
\hline & & & & & & \\
\hline Absent & $8(88.9)$ & $1(11 \cdot 1)$ & $2(20 \cdot 0)$ & $2(18 \cdot 2)$ & $13(33 \cdot 3)$ & $\chi^{2}=16 \cdot 43$ \\
\hline Present & $1(11 \cdot 1)$ & $8(88.9)$ & $8(80.0)$ & $9(81 \cdot 8)$ & $26(66 \cdot 7)$ & $\stackrel{P}{\mathrm{P}}<0.001$ \\
\hline
\end{tabular}

double lung cinescintigraphy measurements was assessed through correlation and regression analysis and $t$ test for paired data. Comparisons between means of the quantitative variables in the four groups were made with analysis of variance (ANOVA). Multiple comparison methods were applied to gain information about the differences between the means. As in some instances there were indications that the assumptions for ANOVA were not satisfied (non-normality, inequality of variances), alternative (or integrative) approaches have been explored: $\log$ and square root transformations of potentially non-gaussian variables, Kruskal-Wallis non-parametric analyses, and degree of freedom adjusted $\mathrm{F}$

Table 3 Comparison of mean spirometric variable in the four groups (ANOVA)

\begin{tabular}{|c|c|c|c|c|c|}
\hline & $n$ & Mean & $S D$ & Min-Max & ANOVA \\
\hline \multicolumn{6}{|l|}{ FVC (1) } \\
\hline Non-exposed & 9 & $3 \cdot 85$ & 0.9 & $2 \cdot 73-5 \cdot 70$ & $F=4.78$ \\
\hline Healthy exposed & 9 & 3.63 & 0.5 & $2 \cdot 75-4 \cdot 25$ & $P<0.01$ \\
\hline Pleural plaques & 10 & 3.02 & $0 \cdot 7$ & $1 \cdot 95-4 \cdot 10$ & \\
\hline Asbestosis & 11 & $2 \cdot 91$ & 0.6 & $2 \cdot 15-4 \cdot 05$ & \\
\hline \multicolumn{6}{|c|}{ FVC $(\Delta \%$ ECCS 1983$)$} \\
\hline Non-exposed & 9 & $94 \cdot 2$ & $10 \cdot 6$ & $84-116$ & $F=4.66$ \\
\hline Healthy exposed & 9 & $92 \cdot 4$ & $13 \cdot 4$ & $67-116$ & $P<0.01$ \\
\hline Pleural plaques & 10 & $83 \cdot 2$ & $12 \cdot 2$ & $67-108$ & \\
\hline Asbestosis & 11 & $76 \cdot 3$ & 12.6 & $59-92$ & \\
\hline \multicolumn{6}{|l|}{$\mathrm{FEV}_{1}(1 / \mathbf{s})$} \\
\hline Non-exposed & 9 & 3.00 & $0 \cdot 7$ & $2 \cdot 02-4 \cdot 50$ & $F=5 \cdot 24$ \\
\hline Healthy exposed & 9 & $2 \cdot 82$ & 0.4 & $2 \cdot 35-3 \cdot 70$ & $P<0.01$ \\
\hline Pleural plaques & 10 & $2 \cdot 25$ & 0.6 & $0.95-2.95$ & \\
\hline Asbestosis & 11 & $2 \cdot 19$ & $0 \cdot 4$ & $1 \cdot 30-2 \cdot 75$ & \\
\hline \multicolumn{6}{|c|}{$\mathrm{FEV}_{1}\left(\Delta \% \mathrm{ECCS}_{1} 1983\right)$} \\
\hline Non-exposed & 9 & $89 \cdot 9$ & $8 \cdot 3$ & $81-109$ & $F=5.76$ \\
\hline Healthy exposed & 9 & $86 \cdot 9$ & $9 \cdot 6$ & $71-100$ & $P<0.01$ \\
\hline Pleural plaques & 10 & $76 \cdot 5$ & $14 \cdot 3$ & $42-92$ & \\
\hline \multirow{2}{*}{\multicolumn{6}{|c|}{$\mathrm{FEV}_{1} / \mathrm{FVC} \%$}} \\
\hline & & & & & \\
\hline Non-exposed & 9 & $77 \cdot 6$ & $5 \cdot 0$ & $70 \cdot 4-84 \cdot 7$ & $F=0.52$ \\
\hline Healthy exposed & 9 & $77 \cdot 9$ & $5 \cdot 7$ & $72 \cdot 0-87 \cdot 1$ & NS \\
\hline Pleural plaques & 10 & $74 \cdot 4$ & $10 \cdot 8$ & $48 \cdot 7-85 \cdot 7$ & \\
\hline Asbestosis & 11 & $75 \cdot 3$ & 6.4 & $60 \cdot 5-82 \cdot 1$ & \\
\hline \multicolumn{6}{|l|}{$\operatorname{PEF}(1 / \mathrm{s})$} \\
\hline Non-exposed & 9 & $7 \cdot 82$ & $1 \cdot 1$ & $6 \cdot 92-9 \cdot 91$ & $F=3.93$ \\
\hline Healthy exposed & 9 & $7 \cdot 19$ & 0.5 & $6 \cdot 28-8 \cdot 25$ & $P<0.05$ \\
\hline Pleural plaques & 10 & $5 \cdot 89$ & $1 \cdot 6$ & $3 \cdot 59-8.65$ & \\
\hline Asbestosis & 11 & $6 \cdot 44$ & $1 \cdot 6$ & $2 \cdot 96-9 \cdot 12$ & \\
\hline \multicolumn{6}{|c|}{ PEF ( $\triangle \%$ ECCS 1983$)$} \\
\hline Non-exposed & 9 & $96 \cdot 7$ & $6 \cdot 1$ & $86-104$ & $F=3.82$ \\
\hline Healthy exposed & 9 & $86 \cdot 9$ & $4 \cdot 0$ & $79-92$ & $\mathrm{P}<0.05$ \\
\hline Pleural plaques & 10 & $75 \cdot 5$ & $18 \cdot 4$ & $49-102$ & \\
\hline Asbestosis & 11 & $79 \cdot 0$ & $15 \cdot 2$ & $41-98$ & \\
\hline \multicolumn{6}{|l|}{$\mathrm{FEF}_{75}(1 / \mathrm{s})$} \\
\hline Non-exposed & 9 & $6 \cdot 21$ & $1 \cdot 7$ & $4 \cdot 23-9 \cdot 18$ & $F=2.5$ \\
\hline Healthy exposed & 9 & $5 \cdot 74$ & $1 \cdot 4$ & $4 \cdot 32-8 \cdot 18$ & NS \\
\hline Pleural plaques & 10 & 4.58 & 1.9 & $0.99-7.29$ & \\
\hline \multirow{2}{*}{\multicolumn{6}{|c|}{$\mathrm{FEF}_{75}(\Delta \%$ ECCS 1983) }} \\
\hline & & & & & \\
\hline Non-exposed & 9 & $85 \cdot 1$ & $17 \cdot 6$ & $60-113$ & $F=2.07$ \\
\hline Healthy exposed & 9 & $79 \cdot 8$ & $16 \cdot 8$ & $60-105$ & NS \\
\hline Pleural plaques & 10 & $66 \cdot 6$ & $27 \cdot 8$ & $16-104$ & \\
\hline Asbestosis & 11 & $65 \cdot 3$ & $20 \cdot 0$ & $25-91$ & \\
\hline \multicolumn{6}{|l|}{$\mathrm{FEF}_{511}(\mathrm{l} / \mathrm{s})$} \\
\hline Non-exposed & 9 & $3 \cdot 34$ & $1 \cdot 0$ & $2 \cdot 26-5 \cdot 22$ & $F=1.97$ \\
\hline Healthy exposed & 9 & 3.03 & 0.9 & $2 \cdot 25-4 \cdot 85$ & NS \\
\hline Pleural plaques & 10 & $2 \cdot 46$ & $1 \cdot 2$ & $0 \cdot 36-4.50$ & \\
\hline \multirow{2}{*}{\multicolumn{6}{|c|}{$\begin{array}{l}\text { Assoestosis } \\
\mathrm{FEF}_{50}(\Delta \% \text { ECCS 1983) }\end{array}$}} \\
\hline & & & & & \\
\hline Non-exposed & 9 & $73 \cdot 3$ & 13.9 & $59-98$ & $F=1.35$ \\
\hline Healthy exposed & 9 & $67 \cdot 6$ & $16 \cdot 1$ & $53-98$ & NS \\
\hline Pleural plaques & 10 & $59 \cdot 3$ & $29 \cdot 7$ & $10-108$ & \\
\hline Asbestosis & 11 & $55 \cdot 8$ & $21 \cdot 0$ & $24-101$ & \\
\hline \multicolumn{6}{|l|}{$\mathrm{FEF}_{25}(\mathrm{l} / \mathrm{s})$} \\
\hline Non-exposed & 9 & $1 \cdot 16$ & $0 \cdot 4$ & $0.61-1.75$ & $F=3.32$ \\
\hline Healthy exposed & 9 & 0.99 & 0.5 & $0.45-1.96$ & $P<0.05$ \\
\hline Pleural plaques & 10 & $0 \cdot 71$ & 0.4 & $0 \cdot 18-1 \cdot 53$ & \\
\hline Asbestosis & 11 & 0.69 & $0 \cdot 2$ & $0 \cdot 36-1 \cdot 17$ & \\
\hline \multicolumn{6}{|c|}{$\mathrm{FEF}_{25}\left(\Delta \% \mathrm{ECCS}_{1983)}\right.$} \\
\hline Non-exposed & 9 & $65 \cdot 9$ & $7 \cdot 6$ & $56-76$ & $F=2.46$ \\
\hline Healthy exposed & 9 & $56 \cdot 2$ & $24 \cdot 5$ & $29-92$ & NS \\
\hline Pleural plaques & 10 & $48 \cdot 3$ & $25 \cdot 9$ & $19-90$ & \\
\hline Asbestosis & 11 & $43 \cdot 3$ & $14 \cdot 7$ & $31-73$ & \\
\hline
\end{tabular}


Table 4 Comparison of means of $\mathrm{PaO}_{2}, \mathrm{PaCO}_{2}, \mathrm{TLCO}_{s b}, \mathrm{DuO}_{2}, \mathrm{DuCO}_{2}$ in the four groups (ANOVA)

\begin{tabular}{|c|c|c|c|c|c|}
\hline & $n$ & Mean & $S D$ & $\operatorname{Min}-\operatorname{Max}$ & $A N O V A$ \\
\hline \multicolumn{6}{|l|}{$\mathrm{PaO}_{2}(\mathrm{~mm} \mathrm{Hg})$} \\
\hline Non-exposed & 9 & 94.9 & 1.4 & $92-97$ & \multirow{4}{*}{$\begin{array}{l}F=14.75 \\
P<0.001\end{array}$} \\
\hline Healthy exposed & 9 & $83 \cdot 4$ & $4 \cdot 6$ & $74-89$ & \\
\hline Pleural plaques & 10 & $83 \cdot 1$ & $6 \cdot 2$ & $70-91$ & \\
\hline Asbestosis & 11 & $79 \cdot 3$ & $6 \cdot \overline{1}$ & $69-89$ & \\
\hline \multicolumn{6}{|l|}{$\mathrm{PaCO}_{2}(\mathrm{~mm} \mathrm{Hg})$} \\
\hline Non-exposed & 9 & $40 \cdot 1$ & $1 \cdot 2$ & $38 \cdot 9-42 \cdot 0$ & \multirow{4}{*}{$\begin{array}{l}F=3.27 \\
P<0.05\end{array}$} \\
\hline Healthy exposed & 9 & $40 \cdot 7$ & 1.4 & $38 \cdot 8-43 \cdot 6$ & \\
\hline Pleural plaques & 10 & $40 \cdot 4$ & $2 \cdot 0$ & $38 \cdot 4-45 \cdot 1$ & \\
\hline Asbestosis & 11 & $42 \cdot 3$ & $2 \cdot 1$ & $39 \cdot 4-46 \cdot 8$ & \\
\hline \multicolumn{6}{|c|}{$\mathrm{TLCO}_{\mathrm{sb}}(\mathrm{ml} / \mathrm{min} / \mathrm{mm} \mathrm{Hg})$} \\
\hline Non-exposed & 9 & $28 \cdot 9$ & 4.9 & $22 \cdot 9-35 \cdot 8$ & \multirow{4}{*}{$\begin{array}{l}F=5.0 \\
P<0.01\end{array}$} \\
\hline Healthy exposed & 9 & $23 \cdot 4$ & $2 \cdot 9$ & $19 \cdot 0-26 \cdot 7$ & \\
\hline Pleural plaques & 10 & $21 \cdot 8$ & $5 \cdot 6$ & $13 \cdot 2-29 \cdot 3$ & \\
\hline Asbestosis & 11 & $22 \cdot 6$ & 3.7 & $17 \cdot 4-28.9$ & \\
\hline \multicolumn{6}{|c|}{$\mathrm{TLCO}_{\mathrm{sb}}(\Delta \%$ ECCS 1983$)$} \\
\hline Non-exposed & 9 & 101.9 & $5 \cdot 1$ & $94-110$ & \multirow{4}{*}{$\begin{array}{l}F=4.43 \\
P<0.01\end{array}$} \\
\hline Healthy exposed & 9 & $86 \cdot 0$ & $10 \cdot 7$ & $70-109$ & \\
\hline Pleural plaques & 10 & $83 \cdot 2$ & $17 \cdot 9$ & $60-110$ & \\
\hline Asbestosis & 11 & $85 \cdot 1$ & $12 \cdot 1$ & $60-104$ & \\
\hline \multicolumn{6}{|l|}{$\mathrm{DuO}_{2}(\mathrm{~mm} \mathrm{Hg})$} \\
\hline Non-exposed & 9 & 0.51 & 0.04 & $0.45-0.59$ & \multirow{4}{*}{$\begin{array}{l}F=7.34 \\
P<0.001\end{array}$} \\
\hline Healthy exposed & 9 & $0 \cdot 40$ & 0.08 & $0.26-0.50$ & \\
\hline Pleural plaques & 10 & $0 \cdot 38$ & 0.08 & $0.24-0.51$ & \\
\hline Asbestosis & 11 & 0.42 & 0.06 & $0.32-0.53$ & \\
\hline \multicolumn{6}{|l|}{$\mathrm{DuO}_{2}(\Delta \%$ predicted $)$} \\
\hline Non-exposed & 9 & $105 \cdot 0$ & $7 \cdot 0$ & $96-119$ & \multirow{4}{*}{$\begin{array}{l}F=3.73 \\
P<0.05\end{array}$} \\
\hline Healthy exposed & 9 & $86 \cdot 0$ & $14 \cdot 5$ & $66-116$ & \\
\hline Pleural plaques & 10 & 84.5 & $19 \cdot 3$ & $55-111$ & \\
\hline Asbestosis & 11 & $88 \cdot 5$ & $15 \cdot 2$ & $63-111$ & \\
\hline \multicolumn{6}{|l|}{$\mathrm{DuCO}_{2}(\mathrm{~mm} \mathrm{Hg})$} \\
\hline Non-exposed & 9 & 0.59 & 0.05 & $0.50-0.67$ & \multirow{4}{*}{$\begin{array}{l}\mathrm{F}=1.29 \\
\mathrm{NS}\end{array}$} \\
\hline Healthy exposed & 9 & 0.55 & 0.08 & $0.40-0.66$ & \\
\hline Pleural plaques & 10 & 0.52 & 0.08 & $0.37-0.66$ & \\
\hline Asbestosis & 11 & 0.59 & $0 \cdot 12$ & $0.48-0.90$ & \\
\hline \multicolumn{6}{|c|}{$\mathrm{DuCO}_{2}(\Delta \%$ predicted $)$} \\
\hline Non-exposed & 9 & $93 \cdot 0$ & $7 \cdot 6$ & 83-106 & \multirow{4}{*}{$\begin{array}{l}F=0.39 \\
N S\end{array}$} \\
\hline Healthy exposed & 9 & $90 \cdot 3$ & $14 \cdot 6$ & $67-113$ & \\
\hline Pleural plaques & 10 & $86 \cdot 7$ & $12 \cdot 3$ & $66-105$ & \\
\hline Asbestosis & 11 & $89 \cdot 8$ & 14.5 & $64-121$ & \\
\hline
\end{tabular}

test. Due to the consistency of the different analyses as far as significance is concerned, results for ANOVA only are reported and discussed. Two way ANOVA was used for the study of the combined influence of exposure and smoking (or chronic bronchitis) on the means of the quantitative variables.

Associations between categorical variables were assessed with the $\chi^{2}$ test. The influence of mucociliary clearance in vivo on the alveolar deposition index was assessed with linear regression methods.

All statistical analyses were performed with SAS. ${ }^{23}$

\section{Results}

In the nine subjects not exposed to occupational respiratory irritants the chest $x$ ray film was negative for any sort of bronchial, parenchymal, or pleural disease, so these subjects were taken as controls.

Nine out of 30 asbestos cement workers had negative chest radiographs for any sort of bronchial, parenchymal, or pleural disease and were thus considered as a group of healthy exposed workers. Chest $x$ ray films showed pleural plaques $(\geqslant a 1)^{11}$ in 10 subjects and diffuse interstitial fibrosis $(\geqslant s 1 / 1)^{11}$ in the remaining 11 subjects. These 11 subjects were classed as workers affected by asbestosis. The entire data analysis was referred to these four groups of workers. None of the subjects had any significant cardiovascular disease. The chest radiographs also showed that none of the 39 selected subjects had abnormal asymmetry of the thoracic skeleton or of the diaphragm, major pleuroparenchymal sequelae of tubercu- losis or other infectious diseases, or monolateral pleural plaques. It was thus possible to exclude the presence of macroscopic morphological or functional differences between the two lungs, therefore cinescintigraphic measurements performed on the right lung only were accepted as representative of both lungs.

Although not exactly identical, the four groups of workers were of similar age and work seniority (table 1). The distribution of the frequency of smoking was also similar and no worker smoked more than 10 pack-years. History of chronic bronchitis and dyspnoea on exercise were more frequent in the three groups of exposed workers than in the nonexposed group, even though the difference was significant only for dyspnoea on exercise (table 2).

Table 3 shows the mean (SD, range) of the spirometric values measured in the four groups of workers, together with the results of their statistical comparisons. The comparisons of mean values of forced vital capacity (FVC), forced expiratory volume in one second $\left(F_{E V}\right)$, and peak expiratory flow (PEF) in the four groups was significant. Furthermore, the subjects with asbestosis had significantly lower mean values of FVC and $\mathrm{FEV}_{1}$ than both healthy exposed and non-exposed groups. Subjects with pleural plaques had significantly lower mean values of $F E V_{1}$ than both healthy exposed and non-exposed groups. The two groups with effects related to asbestos had significantly lower mean values of PEF than the non-exposed group.

The mean arterial oxygen tension $\left(\mathrm{PaO}_{2}\right)$ was significantly lower in the three groups of exposed workers than in the control group 
Figure 1 Lung cinescintigraphy of a nonexposed subject: first image collected at the end of aerosol. It shows the homogeneous distribution lungs. of radioaerosol in the

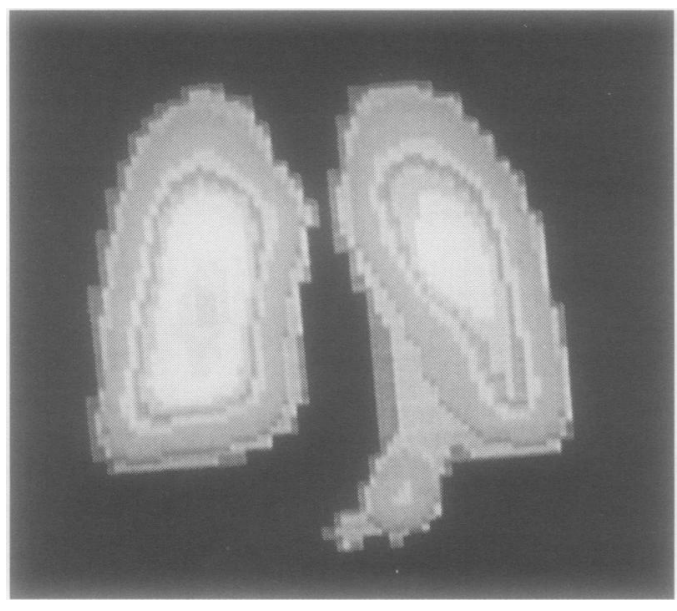
cinescintigraphy of a subject with asbestosis: first image collected at the end of aerosol. It shows the disturbances of the radioaerosol distribution in the lungs.
Figure 2 Lung

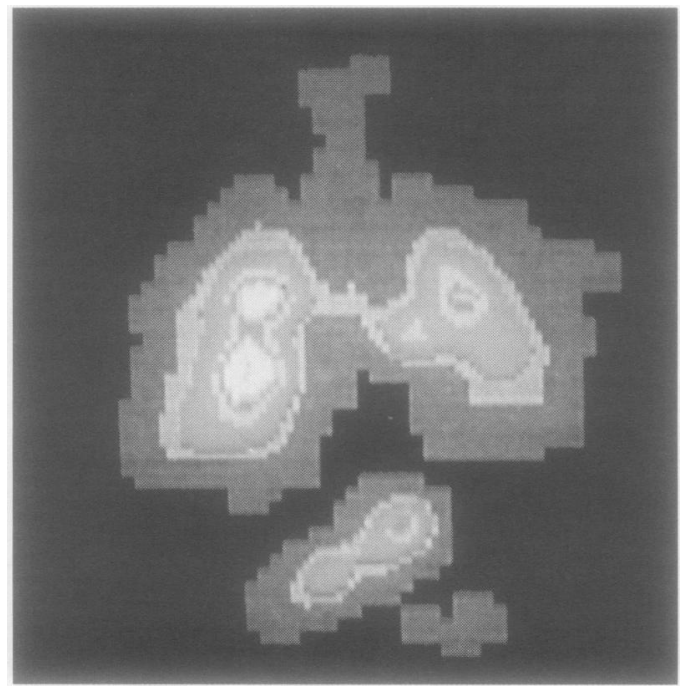

(table 4). The mean arterial carbon dioxide tension $\left(\mathrm{PaCO}_{2}\right)$ was significantly higher in the group of workers with asbestosis than in the three other groups (table 4). The mean values of $\mathrm{TLCO}_{\mathrm{sb}}$ and $\mathrm{DuO}_{2}$ of both measured values and percentage differences compared with the predicted values were significantly lower in the three groups of asbestos cement workers than in the non-exposed workers (table 4). The mean values of $\mathrm{DuCO}_{2}$ were similar in the four groups.

At the end of the aerosol inhalation, total radioactivity in both lungs of each subject was about $110 \mathrm{MBq}$, equivalent to a dose absorbed by both lungs of about $8 \mathrm{mGy}$ (figs 1 and 2). The mean value of the alveolar deposition index was significantly lower in the groups with pleural plaques and asbestosis than in both non-exposed and healthy exposed groups

Table 5 Comparison of means of lung cinescintigraphic variables in the four groups (ANOVA)

\begin{tabular}{lrrrrl}
\hline & $n$ & Mean & \multicolumn{1}{c}{$S D$} & Min-Max & ANOVA \\
\hline Alveolar deposition index (\%): & & & & & \\
$\quad$ Non-exposed & 9 & $84 \cdot 3$ & $2 \cdot 1$ & $80-87$ & $\mathrm{~F}=29 \cdot 42$ \\
Healthy exposed & 9 & $72 \cdot 8$ & 3.9 & $68-80$ & $\mathrm{P}<0.0001$ \\
Pleural plaques & 10 & $56 \cdot 2$ & 12.9 & $39-78$ & \\
Asbestosis & 11 & $36 \cdot 1$ & 18.9 & $3-67$ & \\
Mucociliary clearance time (min): & 9 & $62 \cdot 6$ & 9.8 & $55-84$ & $\mathrm{~F}=22 \cdot 22$ \\
Non-exposed & 9 & 112.7 & 16.7 & $85-141$ & $\mathrm{P}<0.0001$ \\
Healthy exposed & 10 & $131 \cdot 2$ & 27.6 & $84-165$ & \\
Pleural plaques & 11 & 312.5 & 135.7 & $115-579$ & \\
Asbestosis & & & & & \\
\hline
\end{tabular}

(table 5). Furthermore, the mean value of the alveolar deposition index was significantly lower in the groups with asbestosis than in the group with pleural plaques only. The mean value of mucociliary clearance time was significantly higher in workers with asbestosis than in the three other groups (table 5).

When smoking was inserted in the ANOVA model, we could find no difference in any of the considered variables that might, at least partially, be caused by smoking. For this reason we omitted the detailed statistical results (ANOVA by the four exposure groups and smoking) and only the analysis of the exposure factor was reported (tables 3-5).

In a two way ANOVA model with the mucociliary clearance time as a dependent variable and chronic phlegm and the group as independent variables, only the group showed an effect; no interaction resulted between the two independent variables. The same result was found when we used alveolar deposition index as a dependent variable.

For the six subjects who repeated the measurement of mucociliary clearance after two months, the mean of the differences between the measurements was close to zero (mean (SD) $8.833(17.387) ; t 0.508 ; \mathrm{NS})$ and Pearson's correlation coefficient was very high $(r$ 0.955). A plot (not reported) of the differences (observation 1 - observation 2) $v$ the mean value ((observation $1+$ observation 2)/2) suggested a greater variability within subjects at higher levels of mucociliary clearance time.

\section{Discussion}

Subjects were assigned to the four groups on the basis of work history and, in the case of the asbestos cement workers, on the basis of the standardised interpretation of chest radiographs most widely used internationally.

The four groups, which had almost identical work seniority, had similar smoking habits, which can explain the similar frequency of a history of chronic phlegm (chronic bronchitis).

The low variability between the six measurements of mucociliary clearance times repeated after two months (very high correlation coefficient and mean of the differences close to zero) indicates that this cinescintigraphic method is probably reliable independently of the specific conditions in which it was performed, but the variability within subjects indicates the need for a more thorough evaluation (not within the aim of the present study) with more subjects and possibly a wider variability of the base conditions (exposure, smoking, age, etc).

Our method was chosen for two reasons: notable aerosol deposits on the peripheral conduction airways thus allowing the in vivo study of efficiency of mucociliary clearance in those areas; particle size also determines the quantity of the aerosol to reach the terminal and respiratory bronchioles and the alveoli where it deposits, thus allowing measurement of the patency of the respiratory zones of the lung 
which are particularly affected by the inhalation of respirable asbestos fibres.

On the basis of mean particle size of the ${ }^{99 \mathrm{~m} T c}$ labelled aerosol, it could be expected that it would deposit mainly in the respiratory bronchioles and in the alveoli. Nevertheless, in the group of workers with asbestosis, alveolar radioactivity was significantly lower than that in not only the healthy exposed and nonexposed subjects but also in the workers with pleural plaques. Reduction in alveolar deposition index could be due to obstruction of the most peripheral airways, as well as to a reduced distensibility of the lung parenchyma, in subjects already affected with diffuse interstitial fibrosis.

Mucociliary clearance of the small airways was significantly less efficient in the workers with asbestosis than in the three other groups. This finding would seem to confirm in vivo that protracted asbestos exposure produces an alteration of mucociliary clearance of the small airways. The histopathological basis of this impairment could be the squamous metaplasia of the bronchiolar epithelium, as shown experimentally on hamster trachea exposed in vitro to crocidolite. ${ }^{9}$

Costal arcs, interposed between the peripheral parts of the lung and the gamma camera, could not significantly interfere with cinescintigraphic images or with calculation of mucociliary clearance time, because costal arcs can only weakly screen radiations.

Smoking did not seem to have any negative effect on measured respiratory variables, nor did it seem to interfere with occupational exposure, at least from a statistical point of view. Cinescintigraphic methods very similar to the one used in the present study showed that, in normal subjects, smoking did not reduce the efficiency of mucociliary clearance in vivo. ${ }^{17}$ Probably this is due to hypersecretion of mucus which, in a still normal smoker, could facilitate mucociliary transport. Again, with in vivo cinescintigraphic methods it was shown that alterations in mucociliary clearance are more obvious in the central than in the peripheral airways of chronic smokers. ${ }^{24}$ Therefore, the fact that smoking had no influence on the results is likely to be due to the size of the respirable particles in the radioaerosol used, which were expected to deposit mainly on peripheral airways. Moreover, none of the subjects were heavy smokers.

Also chronic bronchitis did not seem to have any negative effect on the mucociliary clearance time, nor did it seem to interfere with occupational exposure, at least from a statistical point of view, and the same result was obtained for alveolar deposition index. This could depend on the fact that chronic bronchitis mainly affects larger airways than the intralobular bronchioles explored with the aerosolised respirable particles used in this study.

In any case, mucociliary clearance in vivo was significantly altered in the workers with asbestosis. The consequent stasis of mucus might therefore contribute in some way to obstruction of the airways. In fact, there was a significant influence of mucociliary clearance time on the index of alveolar deposition of particles $\left(y=0.159 x+86.676 ; R^{2} 0.775\right.$; $\mathrm{P}<0.001)$.

The subjects affected by asbestos related effects showed significant impairment of the main spirometric variables, which is in agreement with recent reports in the international literature. ${ }^{3}$ Further, the means of the percentage variations of FVC, $\mathrm{FEV}_{1}$, and PEF compared with the predicted values were significantly reduced, with impairment not only of the volumes but also of the flow values. These results do in fact confirm that asbestos exposure can cause a chronic obstruction of the airways. On the basis of this functional data it can be deduced that prolonged inhalation of asbestos fibres can cause not only diffuse interstitial and pleural fibrosis, but also fibrosis of the walls of the small airways and thus their obstruction. Also, it cannot be excluded that cement dust itself had a chronic irritative effect on the mucosa of the airways due to the oxidating properties of the components of cement. However, the size of the particles of cement usually mixed with asbestos is mostly in the non-respirable range, with an aerodynamic diameter of $10 \mu \mathrm{m}$ or more, up to $200 \mu \mathrm{m}$. Therefore, most of the cement dust inhaled tends to deposit on, and perhaps irritate, the medium and large conduction airways - that is, in more proximal districts than those explored dynamically in vivo with the cinescintigraphic method used.

A significant reduction in $\mathrm{PaO}_{2}$ compared with the non-exposed group was found not only in the workers already affected with asbestosis but also in the group with pleural plaques and in the group of healthy exposed workers. In our opinion, this result confirms that chronic inhalation of asbestos can cause early morphological or functional alterations of the preterminal and respiratory bronchioles and of the satellite arterioles. ${ }^{2}$ These disturbances produce a shunt effect (lung perfusion passes through hypoventilated bronchiolar districts), which is responsible for the reduced pulmonary oxygenation in the asbestos cement workers whose chest $x$ ray films were still negative for parenchymal asbestosis.

The respiratory origin of this relative hypoxaemia in the three groups of asbestos cement workers was confirmed by the alteration of the alveolar capillary diffusion, as shown by the significant reduction of the mean $\mathrm{TLCO}_{\mathrm{sb}}$ and $\mathrm{DuO}_{2}$ values in the exposed subjects (with or without effects related to asbestos) compared with the non-exposed. Thus $\mathrm{TLCO}_{\mathrm{sb}}, \mathrm{DuO}_{2}$, and arterial blood gas analysis confirm that chronic exposure to asbestos cement can cause morphological or functional disturbances that interfere with regular alveolar capillary exchange of $\mathrm{O}_{2}$. In fact, impairment of alveolar capillary diffusion is a clear early sign of asbestosis.

In the workers with asbestosis the mean $\mathrm{PaCO}_{2}$ value was significantly higher than in the three other groups. This $\mathrm{CO}_{2}$ retention does in fact occur in spite of cardiorespiratory 
compensation of arterial hypoxaemia, however slight. It is likely that the consequent global increase in lung ventilation and perfusion does not result in efficient alveolar ventilation.

The present study therefore confirms that chronic exposure to asbestos cement causes impairment not only of volumes, but also of expiratory flows. Obstruction occurs also in intralobular small airways, the walls of which have probably developed fibrosis as a result of asbestos inhalation. This obstruction and the reduced alveolar distensibility, which is likely to be present in subjects with effects related to asbestos, were responsible for the disturbances of alveolar capillary gas exchange found in all exposed workers. Lung function was further altered by the significant slowing down of mucociliary clearance observed in vivo in the workers with asbestosis. Efficiency of mucociliary clearance is reduced also in the two other groups of exposed workers with respect to the control group, although this result was not significant. The consequent stasis of mucus can enhance obstruction of the airways and hence the disturbances of intrapulmonary distribution of ventilation (figs 1 and 2). Alteration of mucociliary clearance causes a slower removal of the asbestos fibres that deposit on the respiratory epithelium. It is therefore likely that the apparent consequent increase of the internal dose can enhance the effects of asbestos on the airways. Such enhancement could be particularly notable in the presence of the types of asbestos that have greater durability in the lung fluids, such as the amphiboles and to a lesser extent chrysotile, contained in the asbestos mixtures used by the asbestos cement workers examined in the present study. ${ }^{25}$ Finally, only cinescintigraphic variables and $\mathrm{PaCO}_{2}$ values are able to discriminate the group with asbestosis from that with pleural plaques.

In conclusion, these results seem to confirm the feasibility of an in vivo dynamic study, with cinescintigraphic methods, of mucociliary function and bronchiolar alveolar patency in asbestos cement workers. This study also confirms the importance of mucociliary clearance, along with macrophage clearance, in reducing pulmonary retention times and consequently the adverse effects of asbestos. ${ }^{26}$ We acknowledge the Division of Occupational Health of
Cassano Murge (Centro Medico di Ricovero e Cura a Carattere Scientifico) and particularly Dr R Molinini.

\section{Appendix}

If we define as $\mathbf{A}$ the radioaerosol deposited in the conduction airways; $\mathbf{B}$ the radioaerosol deposited in the respiratory bronchioles, alveolar ducts, and alveoli; $t$ the time elapsed from the end of the aerosol; we can define as $\mathbf{R}$ the total radioactivity in the lung regions of interest immediately after administration:

$$
\mathbf{R}_{\mathbf{t}}=\mathbf{A}_{\mathbf{t}}+\mathbf{B}_{\mathbf{t}}
$$

Equation 1, corrected by physical decay of ${ }^{99 m} \mathrm{Tc}$ $(\mathrm{T} / 2=6 \mathrm{~h})$, becomes:

$$
\mathbf{R}_{\mathrm{t}_{\mathrm{c}}}=\mathbf{A}_{\mathrm{t}_{\mathrm{c}}}+\mathbf{B}_{\mathrm{t}_{\mathrm{c}}}
$$

24 hours after the aerosol was given $\mathbf{A}_{t_{c}}=0$ because of mucociliary activity, thus:

$$
\mathbf{B}_{24_{c}}=\mathbf{R}_{24}
$$

As $B_{24 c}$ is constant in the first $24-48$ hours, we can assume that in the two hours after the aerosol:

$$
B_{t_{c}}=B_{24}
$$

Equation 2 can therefore be rewritten:

$$
\mathbf{R}_{\mathrm{c}}=\mathbf{A}_{\mathrm{c}}+\mathbf{R}_{24}
$$

where $\mathbf{R}_{24}$ is a measure obtained experimentally and is specific for each patient.

It follows that:

$$
A_{t_{c}}=R_{\mathbf{c}_{c}}-\mathbf{R}_{24}
$$

The best fit A,s (which take into account ${ }^{99} \mathrm{~m}$ Tc physical decay and radioaerosol alveolar deposition) that our calculator automatically suggested for each subject have a linear progression and so their mathematical expression is:

$$
A_{t_{c}}=k \times t+\text { constant }
$$

where $\mathbf{k}$ values are a regression coefficient-that is, a negative number which is characteristic of that regression line and thus of each patient. This curve shifted from effectively obtained points with an accepted error $<$ $2 \%$.

As $\mathbf{A}_{t_{c}}$ represents only the radioaerosol deposited in the ciliated airways, the value of $\mathbf{k}$ is an index of mucociliary efficiency.

The mucociliary clearance time $\left(\mathbf{T}_{\mathrm{mc}}\right)$ of the radioaerosol deposited in the ciliated tract, when $\mathbf{A}_{\mathbf{t}_{\mathrm{c}}}=$ 0 , can be derived from equation 4 :

$$
\mathbf{T}_{\mathrm{mc}}=\frac{- \text { constant }}{\mathbf{k}}
$$

The value of $\mathbf{T}_{\mathrm{mc}}$ is a further index of mucociliary efficiency, with which it is in inverse proportion.

Therefore, keeping in mind equation 4, we can rewrite equation 2 ' as:

$$
\mathbf{R}_{\mathrm{c}}=\mathbf{k} \times \mathbf{T}_{\mathrm{mc}}+\text { constant }+\mathbf{R}_{24 \mathrm{c}}
$$

This expression represents the experimental curve of the activity-time function of the aerosol in the lung.

In conclusion, with a dose of radioaerosol and analysis of the behaviour of radioactivity in a region of interest of a lung, it is possible to obtain experimentally in vivo in human subjects parametric values for mucociliary elimination time $\left(\mathbf{T}_{\mathrm{mc}}\right)$ and for the alveolar deposition $\left(\mathbf{R}_{24}\right)$ of microcolloids.

Linear mathematical representation of mucociliary clearance confirms that mucociliary apparatus removes deposited xenobiotics from ciliated airways, through a typical mechanical method of transport.

1 Wright JL, Churg A. Severe diffuse small airways abnormalities in long term chrysotile asbestos miners. $\mathrm{Br} \mathcal{F}$ Ind Med 1985;42:556-59.

2 Chiappino G, Bertazzi PA, Beccalossi F. Asbestosi: valutazione degli indicatori non radiologici. Med Lav 1978. 69:281-97.

3 Kilburn KH, Warshaw RH. Airways obstruction from asbestos exposure: effects of asbestosis and smoking. Chest 1994;106:1061-70.

4 Churg A, Wright JL, Wiggs B, Pare PD, Lazur N. Small airways disease and mineral dust exposure: prevalence, structure and function. Am Rev Respir Dis 1985;131: structure

5 Jodoin G, Gibbs GW, Macklem PT, McDonald JC, Becklake MR. Early effects of asbestos exposure on lung function. Am Rev Respir Dis 1971;104:525-35.

6 Warheit DB. Interspecies comparisons of lung responses to inhaled particles and gases. Crit Rev Toxicol 1989;20: 1-29.

7 Oberdoster G. Macrophage-associated responses to chrysotile. Ann Occup Hyg 1994;38:601-15.

8 Woodworth CD, Mossman BT, Craighead JE. Interaction of asbestos with metaplastic squamous epithelium developing in organ cultures of hamster trachea. Environ Health Perspect 1983;51:27-33.

9 Mossman BT, Kessler JB, Ley BW, Craighead JE. Interaction of crocidolite asbestos with hamster respira tory mucosa in organ culture. Lab Invest 1977;36:131-9.

10 Woodworth CD, Mossman BT, Craighead JE. Squamous metaplasia of the respiratory tract. Possible pathogenic 
role in asbestos-associated bronchogenic carcinoma. Lab Invest 1983;48:578-84.

11 International Labour Office. Guidelines of the use of ILO international classification of radiographs of pneumoconiosis. Revised edition 1981. Genève: ILO 1980. (Occupational Safety and Health Series 22.)

12 Minette A. Questionnaire of the European Community for Coal and Steel on respiratory symptoms. Eur Respir $\mathcal{f}$ 1989;2:165-77. 13 American Thoracic

American Thoracic Society Statement. Snowbird workshop
on standardization on spirometry-1987 update. Am Rev on standardization on spirom

14 Lacoste J, Uffholtz H, Pham QT, Sentissi M, Berthet A. Les ductances pulmonaires et les bronchopneumophathies obstructives débutantes. Poumon et Coeur 1975;21:263-5.

15 Di Lorenzo L, Molinini R, Bruno F, De Nicolò $M$, Assennato G, Ambrosi L. Misura delle duttanze globali e parziali ad $\mathrm{O}_{2}$ e $\mathrm{CO}_{2}$ in lavoratori esposti ad inalazione di cemento-amianto. Med Lav 1990;81:32-8.

16 Quanjer PhH, Dalhuijsen A, van Zomeren BC. Summary equations of reference values. Bulletin of European Physiopathology of Respiration 1983;19:45-51.

17 Isawa T, Teshima T, Hirano T, Ebina A, Konno K Mucociliary clearance mechanism in smoking and nonsmoking normal subjects. $f$ Nucl Med 1984;25:352-9.
18 Stahlofen W, Gebhart J, Heyder J. Experimental determination of the regional deposition of aerosol particles in the human respiratory tract. Am Ind Hyg Assoc $\mathcal{F} 1980$; 41:385-98.

19 Pavia D, Bateman JRM, Clarke SW. Deposition and clearance of inhaled particles. Bull Eur Physiopath Respir 1980; 16:335-66

20 Green GM, Jakab GM, Low RB, Davis GS. Defence mechanisms of the respiratory membrane. Am Rev Respir Dis 1977;115:479.

21 Agnew JE, Pavia D, Lopez-Vidriero MT, Clarke SW. Mucus clearance from peripheral airways. Eur $\mathcal{f}$ Respir Dis 1987;71:150-8.

22 Bateman JRM, Pavia D, Sheahan NF, Agnew JE, Clarke SW. Impaired tracheobronchial clearance in patients with mild stable asthma. Thorax 1983;38:463-67.

23 SAS Institut. SASISTAT user's guide. Release 6.03. Cary, NC, USA: SAS Institut, 1988

24 Vastag E, Matthys H, Zsamboki J, Köhler D, Daikeler J. Mucociliary clearance in smokers. Eur 7 Respir Dis 1986; 68:107-13.

25 Churg A. Deposition and clearance of chrysotile asbestos. Ann Occup Hyg 1994;38:625-33.

26 Bégin R, Cantin A, Massé S, Sébastien P. Contributions of esperimental asbestosis in sheep to the understanding of asbestosis. Ann N Y Acad Sci 1991;643:228-38. 